\title{
A Brief Overview of Antimicrobial Nanotextiles Prepared by In Situ Synthesis and Deposition of Silver Nanoparticles on Cotton
}

\author{
Sushilkumar A. Jadhav ${ }^{a, *}$, Aravind H. Patil ${ }^{b}$, Saurabh S. Thoravat ${ }^{a}$, \\ Vinay S. Patil ${ }^{a}$, and Pramod S. Patil ${ }^{a, b, *}$ \\ ${ }^{a}$ School of Nanoscience and Technology, Shivaji University Kolhapur, Vidyanagar, 416004 Kolhapur, Maharashtra, India \\ ${ }^{b}$ Department of Physics, Shivaji University Kolhapur, Vidyanagar, 416004 Kolhapur, Maharashtra, India \\ *e-mail:psp_phy@unishivaji.ac.in; sushil.unige@gmail.com \\ Received December 19, 2020; revised April 1, 2021; accepted April 2, 2021
}

\begin{abstract}
Antimicrobial nanotextiles are prepared by coating or deposition of the biocides such as organic compounds or nanoparticles on the textile fibers. The deposition of silver nanoparticles (AgNPs) on textiles has received increased attention due to their well-known antimicrobial properties. Recently, the technique of in situ synthesis and deposition of AgNPs on cotton is being used frequently to prepare antimicrobial nanotextiles. The technique involves complexation of the $\mathrm{Ag}^{+}$ions in cotton fibers followed by their reduction to generate the particles. This in situ synthesis and deposition approach provides several advantages over the post synthesis deposition or grafting process. In this brief overview, we have presented basic information about different biocides used to prepare antimicrobial nanotextiles and highlighted the importance of in situ synthesis and deposition of AgNPs on cotton to prepare the antimicrobial nanotextiles. The recent achievements in this field and future challenges that need to be addressed are presented.
\end{abstract}

DOI: $10.1134 / \mathrm{S} 2635167621040170$

\section{INTRODUCTION}

The recent outbreak of the COVID-19 virus has urged the need for the development of textiles with antimicrobial properties. The attempts to develop nanotextiles with antimicrobial properties are on since last few years [1]. There is a need to develop durable (long lasting) antimicrobial nanotextiles. Until now, such nanotextiles are prepared mainly by the inclusion of antimicrobial compounds in the polymeric fibers (polyester or cotton) and by the coating (deposition) or grafting (chemical/covalent bonding) of certain moieties such as different nanomaterials onto the fibers. The antimicrobial agents used to prepare commercial textiles have different modes of action according to their chemical and structural nature as well as affinity to bind and destroy the microbial cells. Recently, preparation of antibacterial nanotextiles by the deposition of nanomaterials such as silver nanoparticles (AgNPs) has received increased attention. This is because of their low toxicity to end user and unique antibacterial as well as antifungal activity against various bacteria and fungi $[2,3]$. Some latest reports even prove that AgNPs-deposited cotton can have wound healing properties in addition to antimicrobial property [4]. The recent progress in the preparation of antimicrobial nanotextiles includes development of the in situ synthesis and deposition techniques to prepare the AgNPs and cotton based antimicrobial nanotextiles [5, 6]. Cotton fiber contains 90-95\% cellulose and structurally cellulose is a linear polymer of $1,4-\beta$-D-glucose units linked together [7]. The hydroxyl groups $-\mathrm{OH}$ protruding from the sides of the molecule chain link neighboring chains together by hydrogen bonding and it forms ribbon-like micro fibrils. The cotton fiber is partly crystalline and partly amorphous; the degree of crystallinity is between 70 and $80 \%$ [7]. During the in situ synthesis and deposition of $\mathrm{AgNPs}$, the $\mathrm{Ag}^{+}$ions are first complexed by the hydroxyl groups on cotton and then reduced to form the nanoparticles (Fig. 1). The final distribution of the particles in the fibers and in general on the cotton substrate depends upon the sites of complexation of the $\mathrm{Ag}^{+}$ions as the particle formation takes place where a cluster of ions are complexed. However, there can be considerable difference between the availability of free hydroxyl groups in amorphous and crystalline region for the complexation of the ions. Almost all hydroxyl groups in crystalline region form strong hydrogen bonding hence they may not be available for the complexation of the $\mathrm{Ag}^{+}$ions. So it is speculated that the amorphous region is preferable site for the complexation of the ions and for the formation of the nanoparticles. Presently there is lack of detailed information about this issue. This is directly linked the durability of the resulting antibacterial nanotextiles as nanoparticles formed at strong hydrogen bonding sites can be 
(a) Reduction of $\mathrm{Ag}^{+}$ions in solution

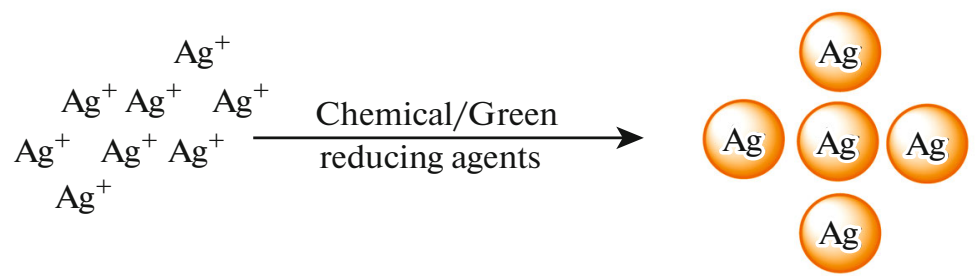

(b) Reduction of $\mathrm{Ag}^{+}$ions complexed in coton fibers

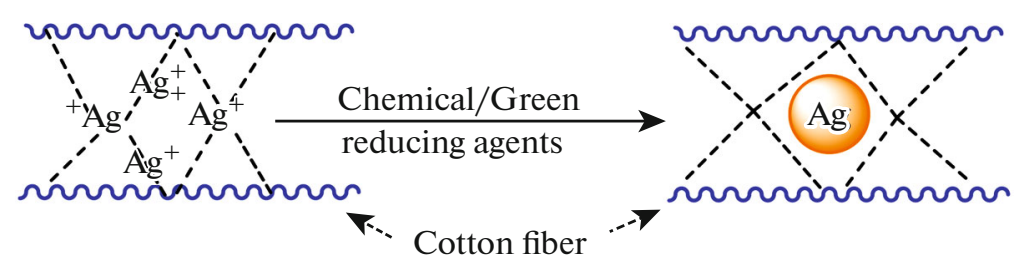

Fig. 1. (Color online) The formation of AgNPs in two different environments.

hold strongly by the fibers for longer time. Hence detailed information obtained through extended research on this will lead to the production of durable antimicrobial nanotextiles. In this brief overview, we have listed the possible biocides with their structures that are used to prepare the antimicrobial nanotextiles, pointed out the importance of nanoparticles (in particular AgNPs) based antimicrobial activity and presented recent progress in this field of AgNPs deposited antimicrobial nanotextiles with challenges that need to be solved in near future.

\section{METHODS TO IMPART ANTIBACTERIAL PROPERTY}

As pointed out earlier, antimicrobial nanotextiles are prepared mainly by the inclusion of antimicrobial compounds in the polymeric fibers (polyester, silk or cotton etc.) and by the coating or grafting of nanomaterials onto the fibers [8]. The table 1 shows list of most commonly used biocides with their chemical structures and their mode of action. Quaternary ammonium compounds (QAC) are cationic (positively charged) surface-active agents that impact cell walls and membranes of microorganisms after coming in contact with them. The positive charge makes them bind to the negatively charged microbes. They have both bactericidal and virucidal (enveloped viruses) activity with good detergency [9]. Chitosan is a natural biopolymer that is cationic in nature and it is made of $N$-acetyl-D-glucosamine and D-glucosamine units connected by $\beta$-1,4-glycosidic linkages. It possesses antibacterial activity and many of its derivatives have been synthesized recently to enhance the activity. In addition, it is also biocompatible, biodegradable and nontoxic in nature $[10,11]$. Poly(hexamethylene biguanide (PHMB) is used as a disinfectant and also as antiseptic [9]. It is a cationic biocide with high chem- ical stability. It can be chemically synthesized by different routes, but most commonly it is obtained by the polycondensation of sodium dicyanamide and hexamethylenediamine in two steps [12]. Triclosan is a member of the halogenated phenoxy phenols. It is an effective chemical against a variety of infectious organisms. It shows antibacterial as well as antifungal activities [13]. When it is deposited on cotton fabrics it shows excellent antibacterial activity [14]. The $N$-Halamines are halogen based antibacterial agents. They are effective against a wide spectrum of microorganisms, they have long-term physicochemical stability and high structural durability [15]. They have also shown antimicrobial efficacies in wound dressings [16]. The main characteristic features of this class of antibacterial agents is they are safe to human and their cost is low $[17,18]$. The nanoparticle mediated antimicrobial activity is discussed in detail in the next section. Importantly all the above mentioned biocides can be deposited on the fibers of various textile materials in use.

\section{NANOPARTICLES AND AgNPs BASED ANTIMICROBIAL ACTIVITY}

As the last row of the Table 1 suggests, recently different nanoparticles have emerged as efficient antimicrobial agents. Both Gram-positive and Gram-negative bacteria have a negatively charged surface. The negative charges present on the bacterial cell walls attract the positively charged nanoparticles of various materials (especially metal or metal oxide nanoparticles) due to electrostatic interactions [19]. The positively charged metal and metal oxide based nanoparticles can interact strongly with the membranes which may result in disruption of cell walls and consequently increase their permeability. The metal or metal oxide nanoparticles attached to the bacterial cells can release 
Table 1. Chemical structure and modes of action of the main antimicrobial agents and the main fibers on which they are used. Reproduced with permission and with suitable corrections and modifications from Morais et al. [1]

\begin{tabular}{ll}
\hline BAC & \multicolumn{1}{c}{ Mode of action } \\
\hline PHMB & $\begin{array}{l}\text { Damage cell membranes; } \\
\text { Denature proteins; } \\
\text { Inhibit DNA production, avoiding multi- } \\
\text { plication } \\
\text { Blocks lipid biosynthesis, affecting the } \\
\text { integrity of cell membranes }\end{array}$ \\
Metal and metal \\
oxide NPs
\end{tabular}

the positively charged metal ions which can enter the cell and disrupt the biological processes. When the metal ions or the nanoparticles enter the cell they can lead to the production of reactive oxygen species (ROS). Due to this, the oxidative stress generated leads to the oxidation of glutathione which suppresses the antioxidant defense mechanism of bacteria against ROS [19]. The possible mechanism of antimicrobial activity of AgNPs are shown in Figs. 2 and 3.

Silver and AgNPs are well-known antibacterial agents [20]. They also have shown wound healing properties [21]. Importantly, silver is nontoxic up to the certain limits and silver nanoparticles can be synthesized by a variety of techniques [22]. The less reactive nature of AgNPs compared to the silver ions makes them suitable for therapeutic applications. There are four known steps of antimicrobial mechanisms of AgNPs. The adhesion of the particles to the surface membrane of microbes followed by the penetration of the AgNPs into the cells that causes the disruption of the biomolecules. They may also induce cellular toxicity by generating ROS which trigger the oxidative stress of cell and disrupt the signal transduction pathways of the bacterial cells. Silver nanoparticle based formulations are used in various antibacterial products in market.

As mentioned earlier, the synthesis and deposition of AgNPs on cotton, polyester and silk fabrics has received a great attention recently to prepare antibacterial nanotextiles. Some recent important breakthroughs are discussed below. The deposition of the silver nanostructures on the textiles can be achieved by two ways, the in situ deposition and post synthesis deposition. The in situ approach provides certain advantages such as small particle size and uniform distribution and hence it is the preferred approach.

\section{RECENT ADVANCES OR BREAKTHROUGH}

Recently, many works reported successful in situ synthesis and deposition of AgNPs on cotton [25-27]. The technique involves soaking of cotton fabric in sil- 


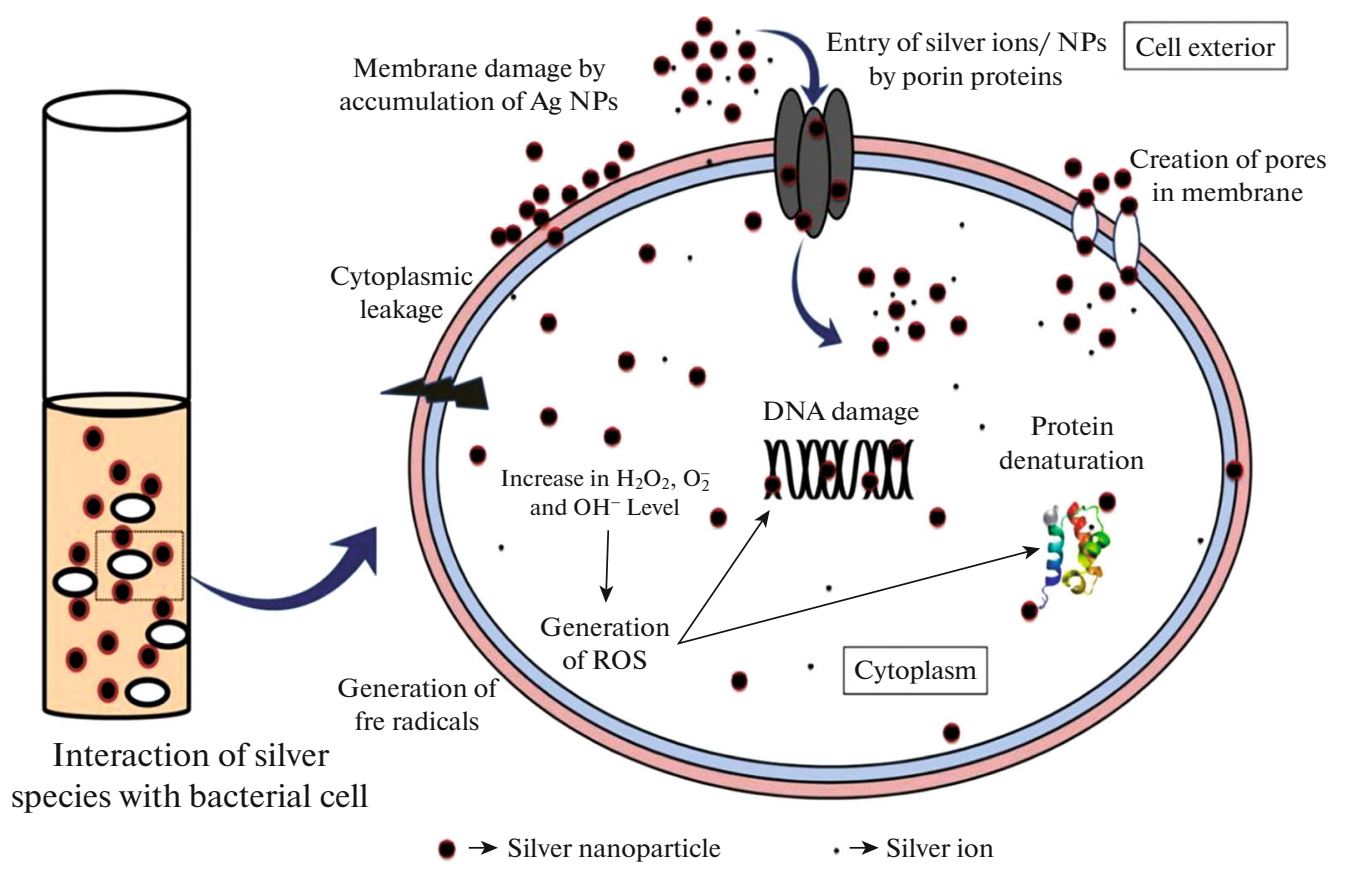

Fig. 2. (Color online) Mechanism of action of AgNPs. Reproduced with permission from Pareek et al. [23].

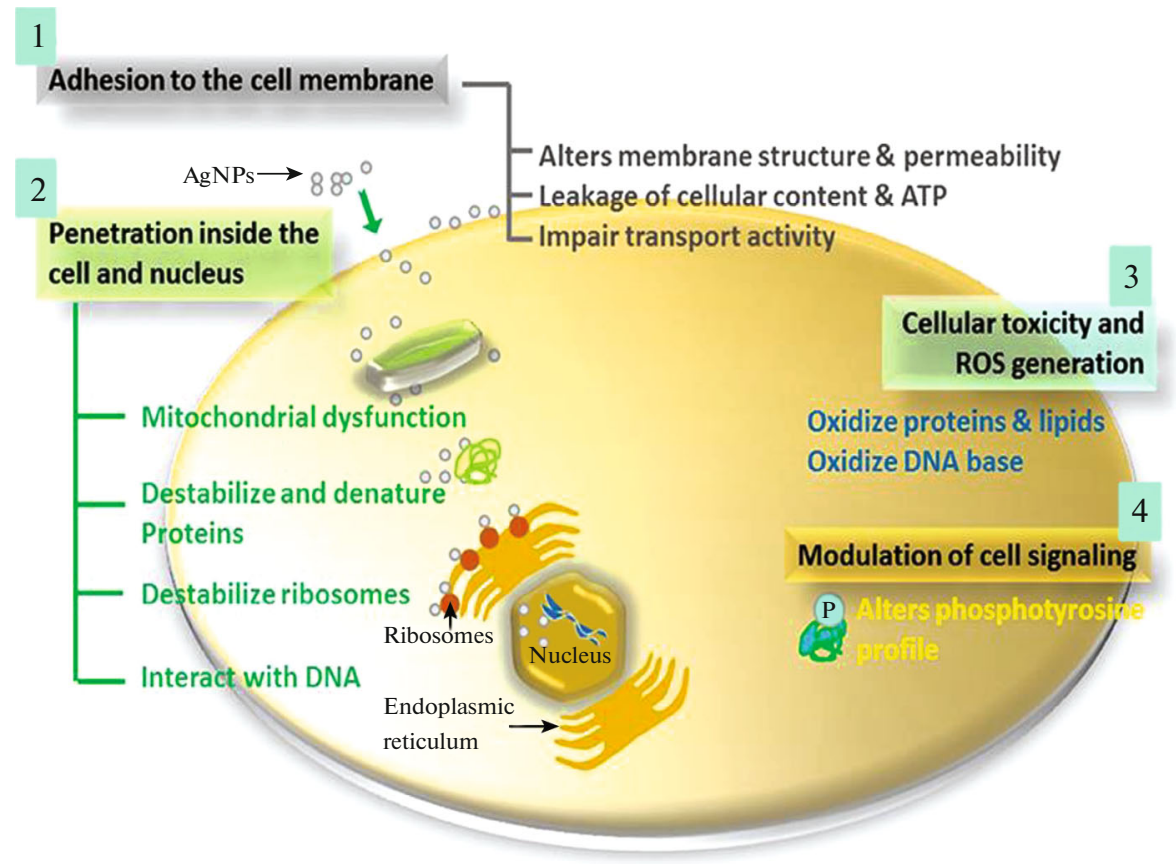

Fig. 3. (Color online) Mechanism of action of AgNPs. Reproduced with permission from Dakal et al. [24].

ver ion solution and subsequent reduction of the ions to form the nanoparticles embedded or trapped strongly inside the fibers or yarns. Various chemical or green (natural) reducing agents have been used so far to obtain the particles [28-30]. The proper incorporation of the nanoparticles in natural textile fibers such as cotton, silk, and wool is challenging process. The post synthesis deposition techniques results in incorporation of the particles on the surface or near-surface regions of the fiber only. Instead, the in situ synthesis and deposition techniques grantees the incorporation of the particles deep inside the fibers (Fig. 4) [31]. It is essentially due to the penetrations of the silver ions which are much smaller in size (compared to particles) 


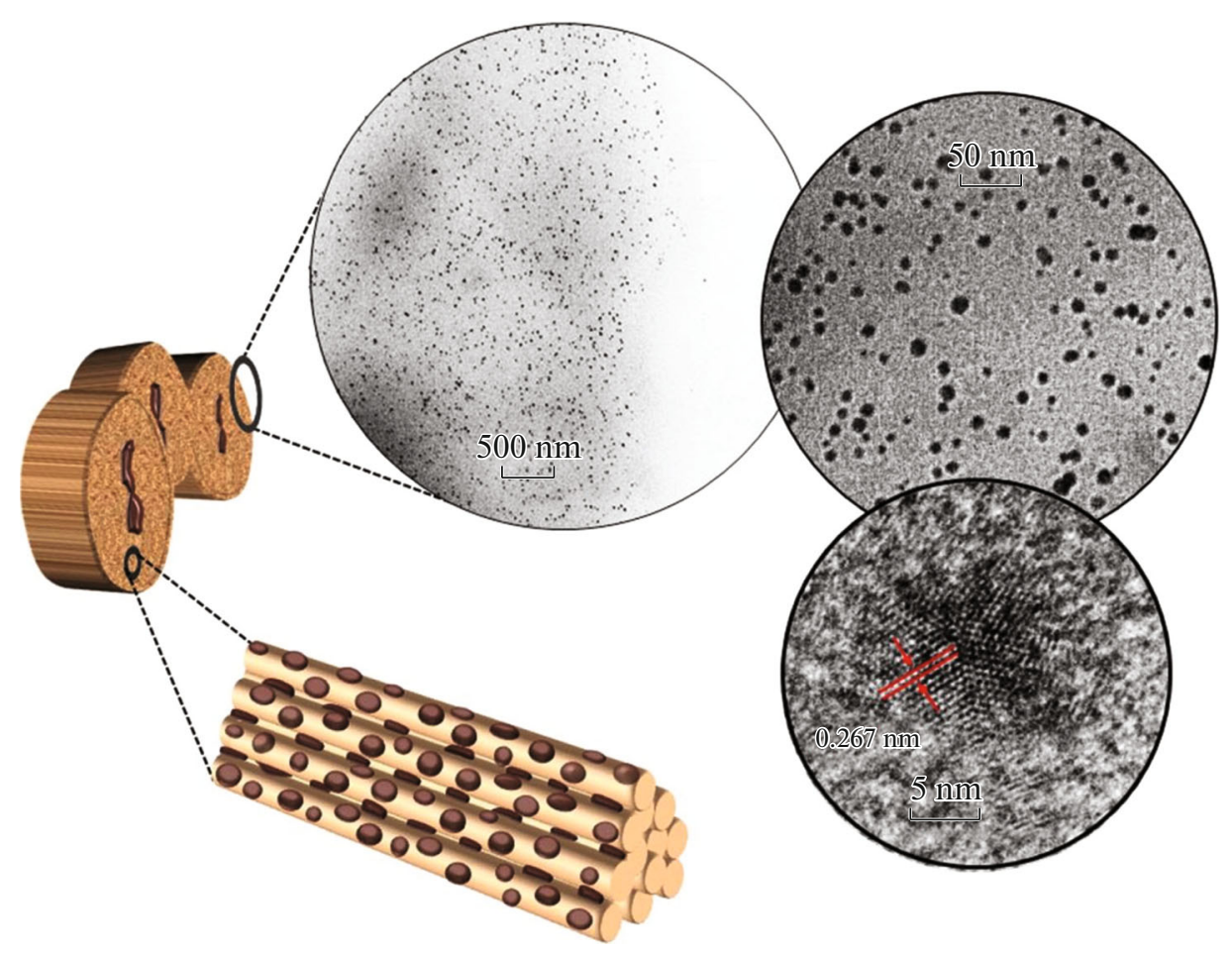

Fig. 4. (Color online) Transmission electron microscopy (TEM) images of the cross-section of silver-cotton nanocomposite fiber showing the internal dispersion of silver nanoparticles and the schematic of the microfibrillar structure of cotton fiber modified by the in situ synthesis of the nanoparticles. Reproduced with permission from Nam et al. [31].

inside the fibers. The process of in situ synthesis and deposition of nanoparticles on cotton is quite similar to some post production operations carried out on raw cotton in the textile industries. Hence, the implementation of this technique in actual textile industrial setup to produce antibacterial nanotextiles (AgNPs-deposited cotton) is feasible.

As mentioned earlier, the in situ synthesis and deposition process results in uniform deposition of the particles on cotton as checked by elemental mapping techniques in the field emission scanning electron microscopy (FESEM) analysis (Fig. 5) [32]. However, elemental mapping cannot show whether the particles are chemically attached (grafted) and strongly hold by the hydrogen bonding or simply physically adsorbed. Further, the location of the particles in crystalline or amorphous region of the cotton fibers cannot be differentiated by this technique. It is highly possible that the nanoparticles formed at the crystalline site may be released early by the cotton fabric due to weak interactions between the particle and the fibers. This is possible due the fact that the strong hydrogen bonding that is present in crystalline region of cotton may make it less preferable site for the complexation of the $\mathrm{Ag}^{+}$ions and subsequent formation of the nanoparticles at that site. Even if the particles are formed there, due the weak interactions of the particles with the fibers they can be easily released by the fibers during actual use.
This reduces the durability of the resulting AgNPsdeposited nanotextiles.

An alternative approach to increase the durability is the chemical grafting of the nanoparticles to the fibers [33-41]. It can be done by bond formation between the particles and cotton fibers [42, 43]. But chemical grafting involves more than one synthetic steps hence the process becomes complicated. Generally it involves functionalization of the nanoparticle or of the fibers of cotton to create a bond between them. A representative example of covalent immobilization of AgNPs on a polymeric substrate is shown in Fig. 6 where covalent assembly of the AgNPs was achieved on a poly(vinylidene fluoride) (PVDF) membrane [44]. The surface of silver and gold have specific interactions with Sulfur in the thiol group which leads the formation of primary bond between them. This bond formation results in covalent grafting of the particles on the substrate $[45,46]$. The post synthesis covalent immobilization (grafting) makes the process multistep and hence it is less preferable. For instance, one such strategy is shown in Fig. 7 [47]. The work involves polymer assisted grafting of the particles on cotton. So to avoid the complex, multi-step and industrially non feasible post synthesis grafting process, there is need to invent in situ synthesis, deposition and chemical bond formation (grafting) techniques in near future. If all these three requirements can be achieved in a single step then it can become an ideal process for 

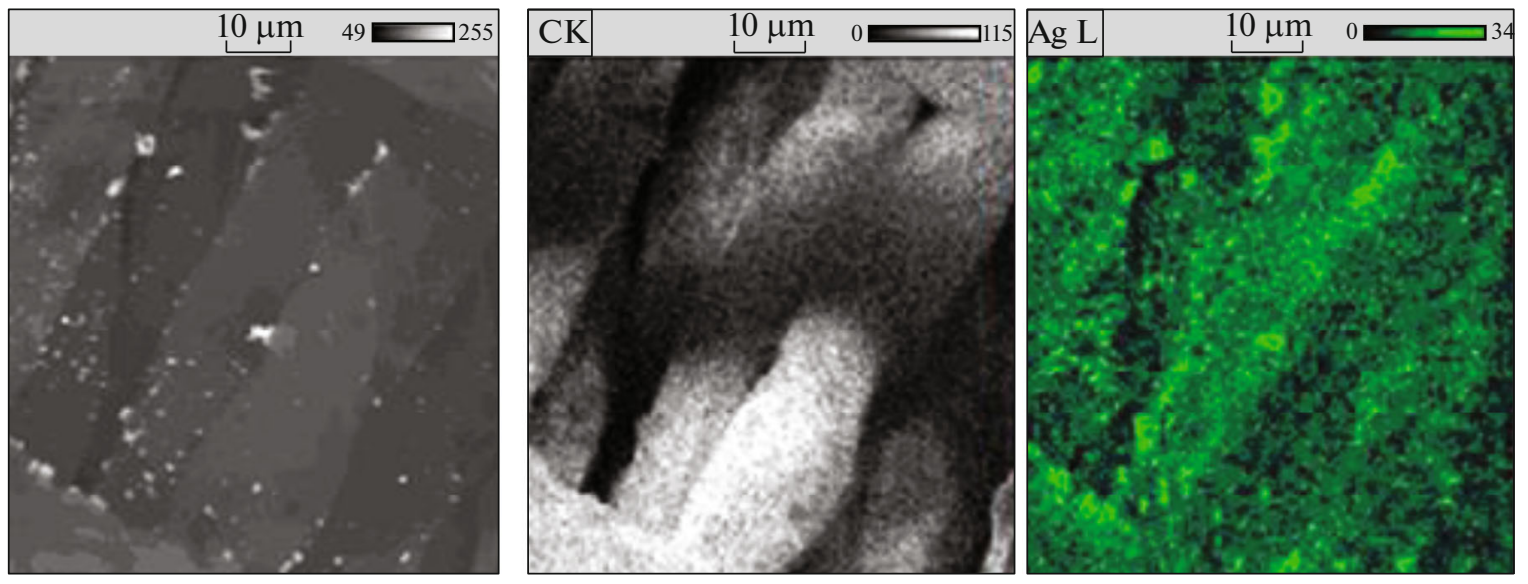

Fig. 5. (Color online) AgNPs-deposited cotton fabric and its elemental mapping (green zone is silver). Reproduced with permission from Bacciarelli-Ulacha et al. [32].
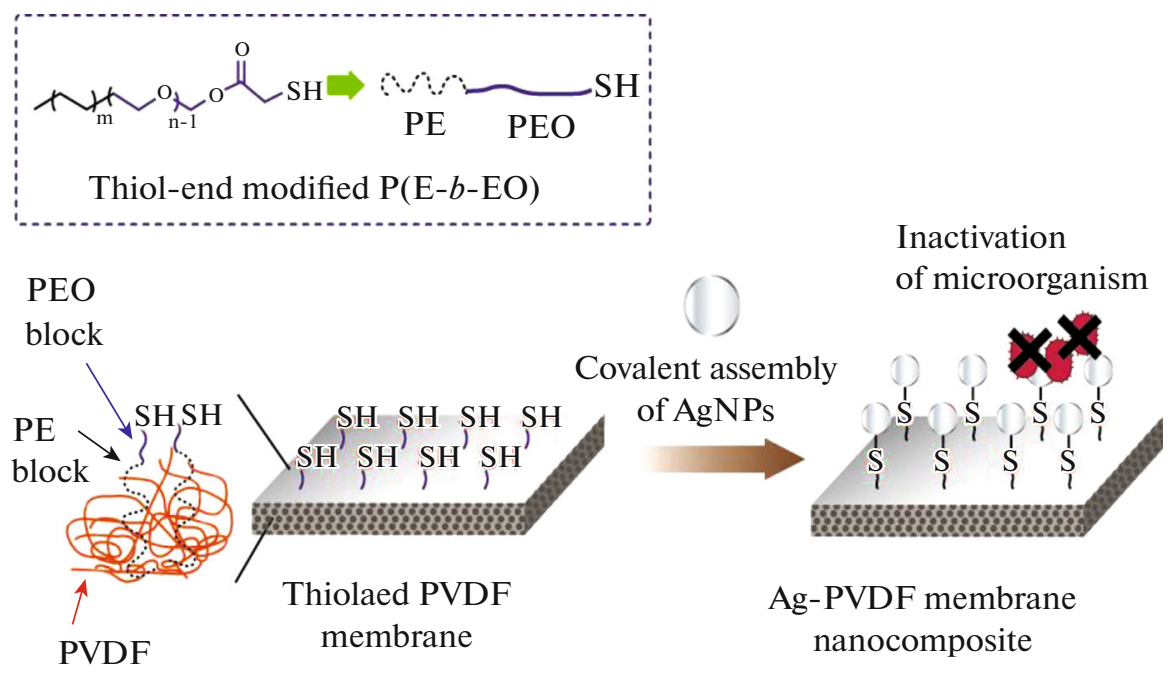

Fig. 6. (Color online) The covalent immobilization of silver nanoparticles (AgNPs) onto poly(vinylidene fluoride) (PVDF) membrane mediated by a thiol-end functional amphiphilic block copolymer linker. Reproduced with permission from Mauter et al. [44].

the preparation of durable antimicrobial nanotextiles. This is highly possible because most of the in situ synthesis and deposition techniques for AgNPs have employed the sonochemical route [48] and bond breaking and bond formation reactions are already reported by sonochemistry or mechanochemistry [49-51]. So there is a need to integrate the knowledge obtained from such reactions with the requirements of the preparation of antimicrobial nanotextiles.

\section{CONCLUSION AND FUTURE CHALLENGES}

Durability is one of the main requirements of antibacterial nanotextiles. The durable antibacterial nanotextiles can be prepared by in situ synthesis and deposition of AgNPs on cotton. Most of the recent works are focused on this approach. The in situ synthesis and deposition process results in uniform deposition of the particles on cotton. Therefore, clear understanding of the possible $\mathrm{Ag}^{+}$ion complexation and subsequent nanoparticle formation sites on cotton fibers is necessary. Another approach of obtaining durable antibacterial nanotextiles is by grafting of AgNPs on cotton. The chemical grafting of the particles needs to be achieved in minimum and simple industrially feasible steps. The chemical environment in the form of available hydroxyl groups for the complexation of silver ions and crystalline or amorphous nature of the site greatly influence the stability of the nanoparticles in the fibers. So one of the major challenge will be to figure out whether the crystalline or amorphous part of the cotton fiber is the preferable nanoparticle formation site. The functionalization of natural cotton to hold the nanoparticles can be another approach but it also need to be achieved in minimum steps. The bond formation between the particles and cotton will 


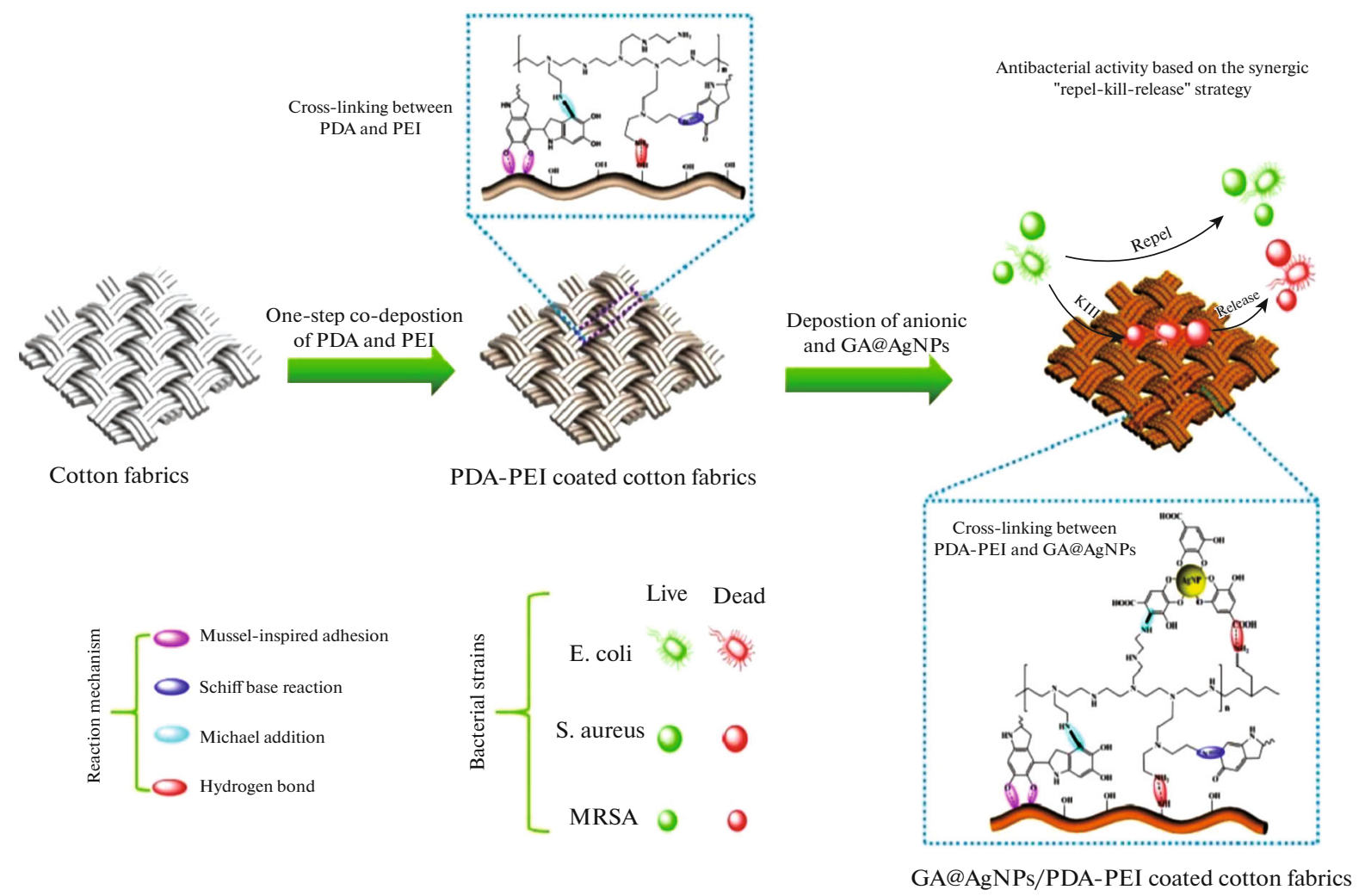

Fig. 7. (Color online) Scheme of preparation of GA@AgNPs/PDA-PEI-coated cotton fabrics and their antibacterial property. Reproduced with permission from Liu et al. [47].

increase the durability of the resulting nanotextiles. As pointed out earlier the development of sonochemical or mehcanochemical methods for the in situ synthesis, deposition and grafting (bond formation with cotton or other textile substrate) of the nanomaterials is also going to be crucial. The emerging area of future nanotextiles will be benefitted from the invention of industrially feasible chemical grafting reactions for the nanomaterials. The extended research along these directions will speed up and benefit the development of durable antimicrobial nanotextiles.

\section{FUNDING}

The financial support to the work by Rashtriya Uchchatar Shiksha Abhiyan (RUSA)'s State Project Directorate (SPD), Mumbai, Maharashtra, India through the center for nanofabrics is gratefully acknowledged. The author AHP thank to Chhatrapati Shahu Maharaj Research Training and Human Development Institute (SARTHI), Pune, Government of Maharashtra for the financial support under the Chief Minister Special Research Fellowship 2019.

\section{CONFLICT OF INTEREST}

The authors declare that they have no conflicts of interest.

\section{REFERENCES}

1. D. S. Morais, R. M. Guedes, and M. A. Lopes, Materials $9,498(2016)$.

https://doi.org/10.3390/ma9060498

2. A. A. Yaqoob, K. Umar, and M. N. M. Ibrahim, Appl. Nanosci. 10, 1369 (2020).

https://doi.org/10.1007/s13204-020-01318-w

3. D. Garg, A. Sarkar, P. Chand, et al., Prog. Biomater. 9, $81(2020)$. https://doi.org/10.1007/s40204-020-00135-2

4. M. Maghimaa and S. A. Alharbi, J. Photochem. Photobiol., B 204, 11206 (2020).

https://doi.org/10.1016/j.jphotobiol.2020.111806

5. S. Mahmud, N. Pervez, M. Abu Taher, et al., Text. Res. J. 90, 1224 (2019). https://doi.org/10.1177/0040517519887532

6. Z. Qi, R. Zhang, J. Lv, et al., Integr. Ferroelectr. 208, $10(2020)$. https://doi.org/10.1080/10584587.2020.1728707

7. A. R. Pasqual and M. E. E. Martin, Cellulose (Intech Open, Rijeka, 2019).

https://doi.org/10.5772/intechopen.75244

8. Y. Gao and R. Cranston, Recent Text. Res. J. 78, 60 (2012). https://doi.org/10.1177\%2F0040517507082332

9. C. L. Schrank, K. P. Minbiole, and W. M. Wuest, ACS Infect. Dis. 7, 1553 (2020).

https://doi.org/10.1021/acsinfecdis.0c00265 
10. P. Sahariah and M. Masson, Biomacromolecules 18, 3846 (2017).

https://doi.org/10.1021/acs.biomac.7b01058

11. M. Chandrasekaran, K. D. Kim, and S. C. Chun, Processes 8, 1173 (2020). https://doi.org/10.3390/pr8091173

12. G. F. de Paula, G. I. Netto, L. Henrique, and C. Mattoso, Polymers 3, 928 (2011). https://doi.org/10.3390/polym3020928

13. P. Shrestha, Y. Zhang, W. J. Chen, and T. Y. Wong, J. Environ. Sci. Health C 38, 245 (2020). https://doi.org/10.1080/26896583.2020.1809286

14. Mehmet Orhan, Eng. Fibers Fabr. J. 15, 1 (2020). https://doi.org/10.1177\%2F1558925020940104

15. A. Dong, Y. J. Wang, Y. Gao, et al., Chem. Rev. 117, 4806 (2017). https://doi.org/10.1021/acs.chemrev.6b00687

16. B. Demir, R. M. Broughton, M. Qiao, et al., Molecules 22, 1582 (2017). https://doi.org/10.3390/molecules22101582

17. Z. Chen and Y. Sun, Ind. Eng. Chem. Res. 45, 2634 (2006). https://doi.org/10.1021/ie060088a

18. F. Hui and C. D. Chouvy, Biomacromolecules 3, 585 (2013). https://doi.org/10.1021/bm301980q

19. E. S. Lopez, E. S. Lopez, D. Gomes, et al., Nanomaterials 10, 292 (2020). https://doi.org/10.3390/nano10020292

20. J. Talapko, T. Matijevic, M. Juzbasic, et al., Microorganisms 8, 1400 (2020). https://dx.doi.org/10.3390\%2Fmicroorganisms8091400

21. F. Paladini and M. Pollini, Materials 12, 2540 (2019). https://doi.org/10.3390/ma12162540

22. M. Ijaz, M. Zafar, and T. Iqbal, Inorg. Nano-Met. Chem. 51, 744 (2020). https://doi.org/10.1080/24701556.2020.1808680

23. V. Pareek, R. Gupta, and J. Panwar, Mater. Sci. Eng. C 90, 739 (2018). https://doi.org/10.1016/j.msec.2018.04.093

24. T. C. Dakal, A. Kumar, R. S. Majumdar, and V. Yadav, Front. Microbiol. 7, 1831 (2016). https://doi.org/10.3389/fmicb.2016.01831

25. A. H. Patil, S. A. Jadhav, K. D. Gurav, et al., J. Text. Inst. 111, 1380 (2020). https://doi.org/10.1080/00405000.2019.1697160

26. A. H. Patil, S. A. Jadhav, V. B. More, K. D. Sonawane, and P. S. Patil, Colloid J. 81, 720 (2019). https://doi.org/10.1134/S1061933X19070019

27. A. G. Thite, K. Krishnanand, D. K. Sharma, and A. K. Mukhopadhyay, Radiat. Phys. Chem. 153, 173 (2018).

28. M. E. Yazdanshenas and M. Shateri-Khalilabad, J. Ind. Text. 42, 459 (2012). https://doi.org/10.1177\%2F1528083712444297

29. Q. Zhou, J. Lv, Y. Ren, et al., Text. Res. J., 1 (2016).

30. E. M. Cruza, M. de la G. Ramosb, C. I. Romo-Saenza, et al., Arch. Oral Biol. 120, 1135 (2020).

https://doi.org/10.1016/j.archoralbio.2020.104943
31. S. Nam, B. D. Condon, C. D. Delhom and K. R. Fontenot, Sci. Rep. 6, 37320 (2016). https://doi.org/10.1038/srep37320

32. A. Bacciarelli-Ulacha, E. Rybicki, E. MatyjasfZgondek, et al., Ind. Eng. Chem. Res. 53, 4147 (2014). https://doi.org/10.1021/ie4011113

33. X. Ding, M. Yu, Z. Wang, et al., Green. Chem. 21, 6611 (2019). https://doi.org/10.1039/C9GC02084E

34. A. Hajlane, H. Kaddami, and R. Joffe, Ind. Crop. Prod. 100, 41 (2017). https://doi.org/10.1016/j.indcrop.2017.02.006

35. S. Y. Park, J. W. Chung, R. D. Priestley, and S. Y. Kwak, Cellulose 11, 2141 (2012). https://doi.org/10.1007/s10570-012-9773-6

36. Q. Xu, R. Li, L. Shen, et al., Appl. Surf. Sci. 497, 143673 (2019). https://doi.org/10.1016/j.apsusc. 2019.143673

37. J. M. Cuevas, B. Gonzalo, C. Rodríguez, et al., J. Exp. Nanosci. 10, 868 (2015). https://doi.org/10.1080/17458080.2014.923587

38. Y. Liu, Y. Li, X. M. Li, and T. He, Langmuir 29, 15275 (2013). https://doi.org/10.1021/la403269u

39. L. Zhang, H. Kong, M. Qiao, et al., Appl. Surf. Sci. 521, 146430 (2020). https://doi.org/10.1016/j.apsusc.2020.146430

40. K. K. Jena, R. Narayan, and K. V. Raju, Prog. Org. Coat. 89, 82 (2015). https://doi.org/10.1016/j.porgcoat.2015.05.022

41. M. E. El-Naggar, A. G. Hassabo, A. L. Mohamed, and T. I. Shaheen, J. Colloid Interface Sci. 10 (2017). https://doi.org/10.1016/j.jcis.2017.03.080

42. D. Zhang, L. Chen, C. Zang, et al., Carbohydr. Polym. 92, 943 (2013). https://doi.org/10.1016/j.carbpol.2012.09.074

43. A. Hebeish, A. El-Shafei, S. Sharaf, and S. Zaghloul, Carbohydr. Polym. 113, 455 (2014). https://doi.org/10.1016/j.carbpol.2014.06.015

44. M. S. Mauter, Y. Wang, K. C. Okemgbo, et al., ACS Appl. Mater. Interfaces 8, 2861 (2011). https://doi.org/10.1021/am200522v

45. S. A. Jadhav, Cent. Eur. J. Chem. 9, 369 (2011). https://doi.org/10.2478/s11532-011-0024-8

46. S. A. Jadhav, Cent. Eur. J. Chem. 10, 295 (2012). https://doi.org/10.2478/s11532-011-0140-5

47. G. Liu, J. Xiang, Q. Xia, et al., Ind. Eng. Chem. Res. 59, 9666 (2020). https://doi.org/10.1021/acs.iecr.9b07076

48. L. Tzounis, P. I. Bangeas, A. Exadaktylos, et al., Nanomaterials 10, 985 (2020). https://doi.org/10.3390/nano10050985

49. M. Lanzillotto, L. Konnert, F. Lamaty, et al., ACS Sustainable Chem., Eng. 3, 2882 (2015). https://doi.org/10.1021/acssuschemeng.5b00819

50. H. Xu, B. W. Zeiger, and K. S. Suslick, Chem. Soc. Rev. 42, 2555 (2013). https://doi.org/10.1039/C2CS35282F

51. T. R. Bastami, A. Ghaedi, S. G. Mitchell, et al., RSC Adv. 10, 16805 (2020). https://doi.org/10.1039/D0RA90056G 